\title{
Distribution of copper-complexing organic ligands in western North Atlantic waters
}

\author{
Xianliang Zhou, Peter J. Wangersky* \\ Department of Oceanography, Dalhousie University, Halifax, Nova Scotia, Canada B3H 4J1
}

\begin{abstract}
Organic materials able to complex ionic copper were extracted from seawater by a technique involving the saturation of complexing sites by the addition of excess ionic copper, followed by adsorption on a Sep-Pak C 18 column. Application of this technique to samples from a series of cruises on the Scotian Shelf covering 3 seasons demonstrated a correlation between biological activity, and particularly phytoplankton productivity, and ligand production. The complexing sites were associated with the polar fraction of organic materials, as determined by compound class separations using the Chromarod-Iatroscan technique.
\end{abstract}

\section{INTRODUCTION}

In previous papers, we have demonstrated that cultured phytoplankton are able to release significant amounts of organic matter capable of complexing copper ions (Zhou \& Wangersky 1985). The release of dissolved organic matter by phytoplankton may be an important source of organic ligands in the sea, although the terrestrial input could be dominant in coastal waters where fresh water runoff is significant (Zhou \& Wangersky 1989 b). Most of the reported distributions of complexation characteristics in open water, such as organic ligand concentrations and stability constants for trace metal-organic complexes, were directly related to phytoplankton productivity (Hirose \& Sugimura 1983, Buckley \& van den Berg 1986, Kramer 1986) or indirectly derived from highly productive surface waters (Mackey 1986).

In this study, we used a modified Sep-Pak C 18 column extraction method and a Chromarod TLC technique (Zhou \& Wangersky 1989a) to study coppercomplexing by organic ligands in the western Atlantic. Our results showed that phytoplankton activity could affect the quality and quantity of these compounds and their distribution patterns.

\section{MATERIALS AND METHODS}

Sampling. Seawater samples were collected in 3 cruises across the Scotian Shelf to the edge of Gulf

\footnotetext{
- Addressee for correspondence
}

Stream, on the CSS 'Dawson', during May, August and November 1986. Sampling stations are shown in Fig. 1. Stn 1 is located on the Scotian Shelf; Stn 2 on the slope;

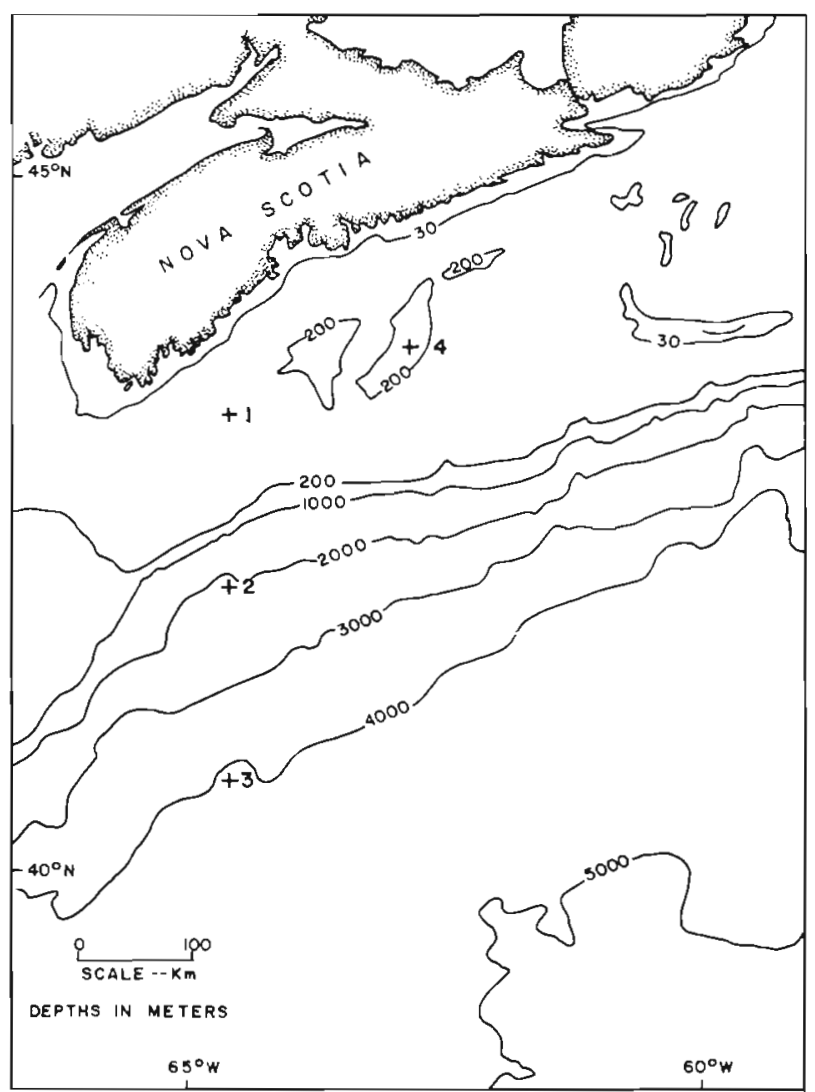

Fig. 1. Sampling stations $(+)$ in the western North Atlantic 
Stn 3 at the edge of the Gulf Stream; and $\operatorname{Stn} 4$ in the Emerald Basin on the Nova Scotian Shelf. Water samples were collected using 5 l Niskin bottles on a rosette sampler.

Sample treatment. Details of the organic ligand isolation and characterization procedures, as well as copper measurement procedures, have been described in an earlier paper (Zhou \& Wangersky 1989a). Samples were collected for measurements of other parameters: dissolved organic carbon (DOC) by a photo-oxidation method (Gershey 1979), particulate organic carbon (POC) by a high-temperature combustion method (Wangersky 1976), and nutrient silicate and phosphate by spectrophotometric methods (Parsons et al. 1984).

\section{RESULTS}

\section{Spring cruise}

The eluent for the Sep-Pak C18 column used during this cruise was methanol, which tends to desorb more non-polar organic compounds but fewer polar ones than the methanol-water (MW) eluent used on later cruises. Thus values reported in this first cruise would give an under-estimation by a factor of 0.7 to 0.8 compared to those in the later cruises (Zhou \& Wangersky 1989a).

In the shelf station (Stn 1) silicate was depleted, at only $0.5 \mu M$, in the top $20 \mathrm{~m}$. POC was high in the upper $40 \mathrm{~m}$, with a broad subsurface maximum, more than $360 \mu \mathrm{g} \mathrm{C} \mathrm{l}^{-1}$ between 20 and $40 \mathrm{~m}$. The concentration of extractable copper-complexing organic ligands, [L], and DOC were also high in the upper $40 \mathrm{~m}$, with a subsurface [L] maximum at $40 \mathrm{~m}$, coincident with the distribution of POC. Profiles of salinity and temperature did not demonstrate dramatic changes between surface and bottom waters

In the slope station (Stn 2), silicate concentration was high compared with the shelf station, up to $4.8 \mu M$ at $20 \mathrm{~m}$ within the wind-mixed layer (about $40 \mathrm{~m}$ ), decreasing towards the surface. The POC profile was a mirror image of that of silicate, i.e. higher towards the surface, $213 \mu \mathrm{g} \mathrm{C} \mathrm{I}^{-1}$ at $10 \mathrm{~m}$, and decreasing rapidly with depth. [L] and DOC had similar distribution patterns, and both were related to that of POC, with the highest values at the surface and low but relatively constant values below the mixed layer.

In the station at the edge of the Gulf Stream (Stn 3), there was a thick layer of warm salty water in the top $250 \mathrm{~m}$, with a well-defined low-salinity surface mixed layer of about $25 \mathrm{~m}$. Silicate concentration was high and constant, between 3.5 and $4.0 \mu \mathrm{M}$ in the top $100 \mathrm{~m}$, except for a region of $3 \mu \mathrm{M}$ at $1 \mathrm{~m}$. POC was low, below $40 \mathrm{~kg} \mathrm{C} 1^{-1}$. [L] and DOC values were low in this water, even in the shallow wind-mixed layer, less than $4.6 \mathrm{nM}$ for $[\mathrm{L}]$ and $0.72 \mathrm{mg} \mathrm{Cl}^{-1}$ for DOC. The exception is water at $1 \mathrm{~m}$, where [L] and DOC were higher, 6.3 and 0.92 respectively.

There were significant correlations between [L] and POC $(r=0.83)$ and between [L] and DOC $(r=0.91)$ during this cruise (Fig. 2). The distribution of points
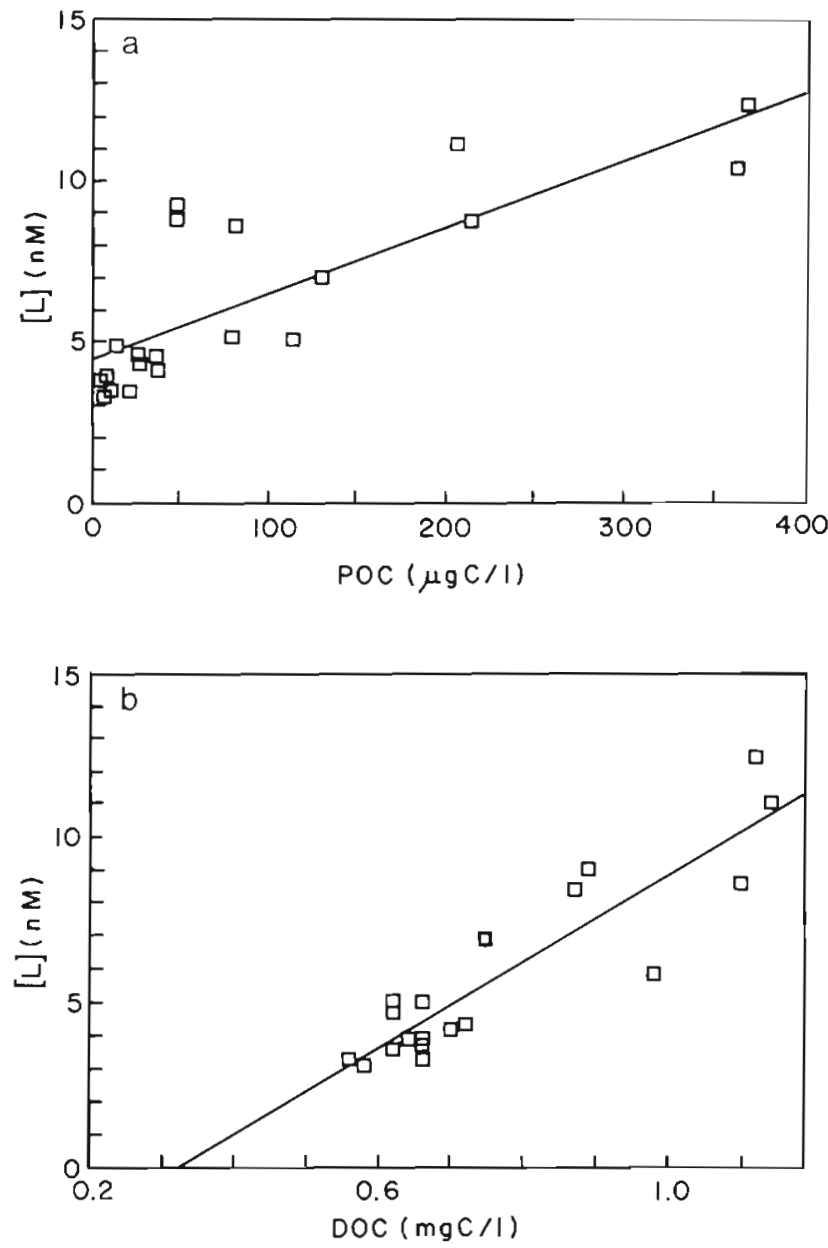

Fig. 2. Spring cruise (a) Correlations between [ $L$ ] and POC; (b) correlations between [L] and DOC

along the whole length of the regression demonstrates that the high degree of correlation was not caused simply by a group of high values in the surface waters and low values in deeper waters.

\section{Summer cruise}

In the shelf station, the bottom of the pycnocline (or thermocline) was ca $35 \mathrm{~m}$, which was the depth of the top of the nutriclines of silicate and phosphate. The [L] value was high, ranging from 8 to $14 \mathrm{n} M$, with a broad maximum between 15 and $45 \mathrm{~m}$ which peaked at $13.9 \mathrm{nM}$ at a depth of $35 \mathrm{~m}$. DOC did not change much throughout the water column, with only a slightly 
higher value at $35 \mathrm{~m}$. Peak POC was at $25 \mathrm{~m}$, which did not exactly coincide with those of [L] and DOC. Over the depths of the [L] maximum POC was also high, 90 to $180 \mathrm{ug} \mathrm{Cl}^{-1}$.

At the slope, the upper $80 \mathrm{~m}$ layer is the coastal water mass, with a sharp thermocline ending at $40 \mathrm{~m}$, which again is the top of the nutriclines. Between 100 and $300 \mathrm{~m}$ there was a layer of warm slope water (Smith et al. 1978). In upper coastal water, organic ligand concentration, DOC, and POC were high, but decreased rapidly with depth. Nutrient concentrations in the mixed layer $(30 \mathrm{~m})$ were depleted, $0.9 \mu \mathrm{M}$ for silicate compared to 3 to $5 \mu M$ on the May cruise. The most striking feature is that at the top of the nutricline (i.e. the bottom of the thermocline, $40 \mathrm{~m}$ ), there was a subsurface biomass (POC) maximum. Associated with this were the subsurface maxima of [L] and DOC. The situation in the station at the edge of Gulf Stream was similar to that in the slope station, i.e. strong pycnocline and nutriclines were developed at a depth of about $50 \mathrm{~m}$, which coincided with the depth of POC and [L] maxima.

There is an apparent correlation between [L] and POC (Fig. 3), which is not linear but displays a saturation-type curve, while [L] and DOC display a close linear correlation $(r=0.95)$ (Fig. 3).

\section{Fall cruise}

During this season, a wind-mixed layer developed at all stations. Nutrient concentrations were low in surface waters, between 1.2 and $1.7 \mu M$ for silicate, but slightly higher than those in the summer cruise, 0.5 to $0.9 \mu M$. POC and DOC data are unfortunately not available. Distribution patterns of organic ligand in all 4 profiles in this cruise are similar, i.e. high and relatively constant in the wind-mixed layer, with the maxima at the shallowest depth e.g. 14.2 to $14.3 \mathrm{nM}$ in the upper $30 \mathrm{~m}$ in shelf water; 12.1 to $12.6 \mathrm{n} M$ in the upper $30 \mathrm{~m}$ in slope water; 10.6 to $10.7 \mathrm{n} M$ in the upper $25 \mathrm{~m}$ in the Gulf Stream; and 13.2 to $13.3 \mathrm{nM}$ in the upper $25 \mathrm{~m}$ in the Emerald Basin (Stn 4). [L] values decrease rapidly in this layer, especially for slope and Gulf Stream stations.

Four types of samples were analyzed using the Chromarod TLC technique. These samples were: shelf surface water (5 to $30 \mathrm{~m}$ ); open surface water (10 to $50 \mathrm{~m})$; open intermediate water $(200$ to $250 \mathrm{~m})$ and deep water (1500 to $2000 \mathrm{~m}$ ) (Table 1). The distribution of organic carbon isolated by adsorption on Sep-Pak C 18 and measured by flame ionization detection (FID) showed a trend similar to that of $[\mathrm{L}]$ in open water, i.e. higher in the surface, up to $67 \mu \mathrm{g} \mathrm{Cl}^{-1}$, and low in the intermediate and deep waters, 37 and $26 \mu \mathrm{g} \mathrm{C} \mathrm{l^{-1 }}$
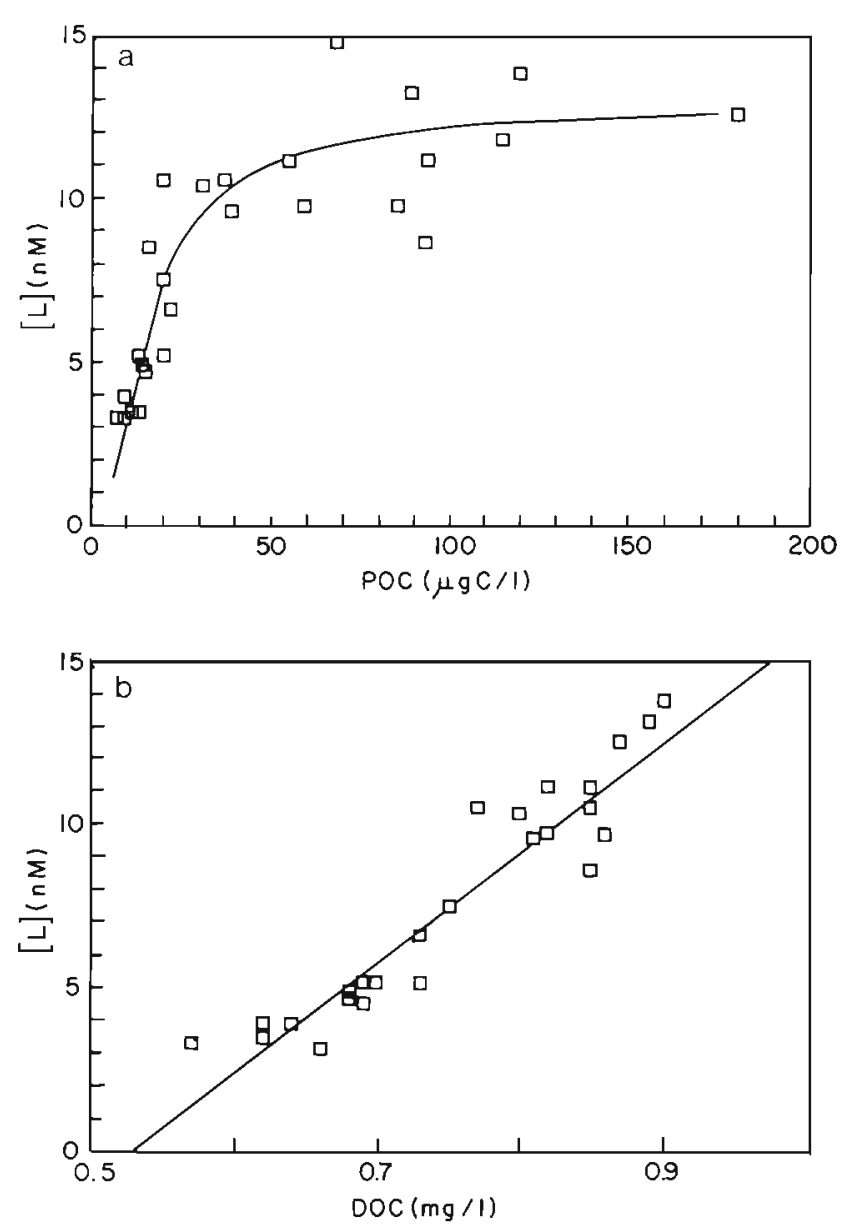

Fig. 3. Summer cruise (a) Correlations between [L] and POC; (b) correlations between [L] and DOC

respectively. Organic material isolated from the surface had a higher specific copper-complexing capacity ( $\mathrm{n} M$ $\mathrm{MgC}^{-1}$ ) than that from deep water. In addition, TLC characterization showed that the proportion of organic carbon and copper-complexing sites in the basemobile' fraction was higher in surface water than in deep waters, from $62 \%$ of organic carbon and $20 \%$ of the complexing sites in surface water, to $57 \%$ and $10 \%$ in deep water. Compared with open surface water, shelf surface water had a higher specific complexing capacity, and higher ratio of the fractions of 'methanolmobile' to 'acid-mobile' in both organic carbon and complexing sites.

\section{DISCUSSION}

\section{General features}

The Sep-Pak C18 extractable organic ligand concentration was much higher, usually more than $10 \mathrm{nM}$, in the surface euphotic zone, and low but relatively con- 
Table 1. Autumn cruise. TLC characterization of organic ligands. A: shelf water, 5-30 m; B: open surface water, 10-50 m; C: open intermediate water, $200-250 \mathrm{~m}$; D: open deep water, $1500-2000 \mathrm{~m}$

\begin{tabular}{|c|c|c|c|c|}
\hline Sample & Base-mobile & Methanol-mobile & Acid-mobile & Total \\
\hline \multicolumn{5}{|c|}{ Organic carbon, $\mu g \mathrm{C}^{-1},(\%$ of total $)$} \\
\hline $\mathrm{A}(\mathrm{n}=4)$ & $43.2 \pm 2.7(66)$ & $14.4 \pm 0.2(22)$ & $7.9 \pm 0.1(12)$ & 65.5 \\
\hline$B(n=4)$ & $41.9 \pm 2.9(62)$ & $12.0 \pm 0.1(18)$ & $13.3 \pm 1.4(20)$ & 67.2 \\
\hline$C(n=4)$ & $20.7 \pm 2.2(55)$ & $7.0 \pm 0.3(19)$ & $10.1 \pm 1.4(26)$ & 37.8 \\
\hline$D(n=4)$ & $14.8 \pm 1.6(57)$ & $6.2 \pm 0.4(24)$ & $5.0 \pm 0.3(19)$ & 26.0 \\
\hline \multicolumn{5}{|c|}{ Organic ligands, $\mathbf{n} M(\%$ of total $)$} \\
\hline $\mathrm{A}(\mathrm{n}=4)$ & $2.6 \pm 0.3 \quad(19)$ & $7.6 \pm 0.1(56)$ & $3.3 \pm 0.2(25)$ & 13.5 \\
\hline$B(n=10)$ & $2.4 \pm 0.4 \quad(20)$ & $5.1 \pm 0.2(42)$ & $4.5 \pm 0.1(38)$ & 12.0 \\
\hline$C(n=4)$ & $0.53 \pm 0.01(11)$ & $2.4 \pm 0.1(47)$ & $2.1 \pm 0.1(42)$ & 5.1 \\
\hline$D(n=4)$ & $0.34 \pm 0.06(10)$ & $1.7 \pm 0.2(49)$ & $1.4 \pm 0.1(41)$ & 3.4 \\
\hline \multicolumn{5}{|c|}{ Copper-complexation capacity, $\mathrm{n} M \mu \mathrm{gC}^{-1}$} \\
\hline A & 0.060 & 0.53 & 0.42 & 0.21 \\
\hline B & 0.057 & 0.43 & 0.34 & 0.18 \\
\hline $\mathrm{C}$ & 0.026 & 0.34 & 0.21 & 0.13 \\
\hline D & 0.023 & 0.27 & 0.28 & 0.13 \\
\hline
\end{tabular}

stant below the thermocline, between 3.5 and $5 \mathrm{nM}$. This type of distribution has been reported in the literature for copper-complexing organic ligand concentrations in the North Atlantic (Buckley \& van den Berg 1986, Kramer 1986) and for organic copper concentrations in the western North Pacific (Hirose \& Sugimura 1983). This pattern of vertical profiles of copperorganic complexation has been attributed to production of organic ligands by phytoplankton in surface water. However, little information on biological or biochemical parameters was reported in previous studies and explanations given were speculative.

In this study, some biologically related and hydrographic parameters were measured e.g. POC, DOC, nutrients, salinity and temperature. It was shown that the distributions of organic ligand concentration were closely related to those of other biochemical parameters, with similar distribution patterns and the same or similar depths of maxima. This close coupling between [L] and POC (as a phytoplankton biomass indicator) and DOC would confirm speculation on the influence of phytoplankton activity on the organic ligand concentration and its distribution.

On the other hand, organic ligand concentrations in intermediate and deep waters were low and relatively constant in open regions. The average age of DOM in deep oceanic water has been estimated to be about 3400 yr (Williams et al, 1969), suggesting that most of the DOM in deep water is refractory and that there is little input of new DOM. The low and relatively constant [L] is thus to be expected in deep water.

The correlation between [L] and POC was positive and significant during the spring cruise (Fig. 2), suggesting the importance of production of organic ligands by phytoplankton. For the summer cruise, however, it was a saturation-type curve rather than linear. Since the [L] value measured the accumulated result of both production and consumption of these organic compounds over a long period of time, higher biomass (or POC) may imply a higher production rate at that moment, but the accumulated [L] may still be low. The steep slope on the low POC section could reflect the distinct difference between deep water, where there is little new DOM input, and surface water, where there is constant input of new DOM from phytoplankton activity. The constant value in the high POC section suggested that biological consumption more or less balances the production of these copper-complexing organic compounds in the euphotic zone, or that the production rate of these compounds was related not only to biomass, but also to species present and to the physiological state of phytoplankton.

There were close correlations between [L] and DOC in the spring and summer cruises, with positive intersections at the DOC axis (Figs. 2 and 3 ). If we consider the DOM content and [L] in seawater as a background fraction, represented by the deep water value, plus a new input fraction due to biological activity, which is responsible for the increase in [L] and DOC, then the linear correlation between [L] and DOC suggested that the new input had similar chemical characteristics throughout the water column. In addition, the positive intersection on the DOC axis suggested that this fraction had a higher complexation capacity, i.e. higher [L]/ DOC ratio, than the background fraction. This is in agreement with the result of culture experiments, that the new organic matter produced by cultured phytoplankton has a higher specific complexation capacity than the bulk organic in natural seawater (Fisher \& Fabris 1982) 
With the direct Sep-Pak C18 column extraction method, organic copper concentration in open surface waters has been reported to be not significantly different from that in deep water in the North Atlantic and even lower than that in deep water in the North Pacific (Donat et al. 1986). These results are in contrast to another set of data of Donat et al. (1986) using electrochemical techniques, showing that most of the dissolved copper $(>90 \%$ ) was associated with organic ligands in surface water, while a relatively small fraction (20 to $30 \%$ ) was so associated in deep waters. Thus they concluded that organic ligands in surface water had a lower isolation efficiency than those in deep waters.

This conclusion seems a little surprising. The DOC values in our study varied considerably through the water column, usually by less than a factor of 2 , but the organic carbon isolated by Sep-Pak C 18 from the surface water was more than 2.5 times that from deep water (Table 1). This suggested that organic matter from surface water was collected more efficiently than that from deep water. The different isolation efficiency may be due to the modification of this column extraction method; the $\mathrm{Cu}^{2+}$ spiking of the seawater sample would saturate most of the copper-complexing sites and may thus change the hydrophilic properties of organic ligands, enhancing the adsorption of organic ligands onto the hydrophobic C18 phase (Plavšić \& Branica 1986, Zhou \& Wangersky 1989a).

\section{Seasonality}

In this study, 3 cruises covering 3 seasons and a variety of watermasses provided an opportunity to study the seasonality of the organic ligand concentration and the distribution pattern in the marine environment. To our knowledge, this kind of study has not yet been reported in the literature.

Organic ligand concentration in seawater is an accumulative result of production by phytoplankton and consumption due to biological degradation of these organic compounds. The seasonal changes in [L] and distribution pattern should reflect the seasonality of biological activity in response to the seasonality of meteorological condition e.g. solar radiation and wind stress.

In temperate waters, as in the area of this study, with the onset of spring, water column stability increases due to a reduction in storm-mixing, and the critical depth deepens due to increasing solar radiation. Since there is a high nutrient concentration in surface water, brought up from the deep water during the winter season, phytoplankton activity would increase significantly (i.e. a spring bloom) as soon as the critical depth extends beneath the wind-mixed layer (Riley 1942 , Sverdrup 1953). The spring bloom usually appears first in shallow coastal water and gradually propagates across the shelf to the open water (Ryther 1963). The situation in the spring cruise was just as expected. In the shelf station, the spring bloom was already in a late stage, as suggested by the low nutrient concentration in surface water and high subsurface POC maximum. [L] was high in this station, with a subsurface maximum coinciding with those of POC and DOC.

In slope water, the spring bloom was only in an early phase, or perhaps had not yet started, as shown by the near surface maximum of POC and the relatively high silicate concentration within the surface mixed layer, with decreasing values towards the surface. The [L] and DOC profiles demonstrated a pattern similar to that of POC, i.e. a maximum near the surface, decreasing rapidly with depth. Nutrient concentration was high and constant in the top $100 \mathrm{~m}$ layer and POC values were low even in the surface mixed layer, except at the $1 \mathrm{~m}$ depth. As a result, [L] and DOC were low and close to those in the intermediate and deep water at this station, except at a depth of $1 \mathrm{~m}$. The late arrival of the spring bloom is a little surprising, considering the shallow $(30 \mathrm{~m})$ mixed layer in this station. Possibly the shallow mixed layer was newly developed by heavy rain or a recent movement of coastal water.

Levels and distribution patterns of [L] have obviously resulted from different levels and distribution patterns of phytoplankton bloom activity. Thus by incorporating the 3 situations relating to the 3 bloom phases at the 3 stations into one single picture, we can see the manner in which a spring phytoplankton bloom affects organic ligand concentration and distribution in the marine environment. A conclusion derived from the results of this cruise is that the production of organic ligands by bloom phytoplankton is significant, in good agreement with time-series observations of spring blooms (Zhou \& Wangersky 1989b) and results of many culture experiments (e.g. McKnight \& Morel 1979, Fisher \& Fabris 1982, Zhou \& Wangersky 1985, Seritti et al. 1986).

In the summer season, the water column is stratified due to fewer storm events and greater heating from solar radiation. The nutrient resupply from the deep water to the euphotic zone is limited and nutrient concentration is depleted in surface water. As a result, a subsurface biomass maximum is often found around the pycnocline (or thermocline), where phytoplankton could still grow with enough light, and adequate nutrients supplied by diffusion through the pycnocline. This situation was found in all 3 stations in the summer cruise, with the tops of the nutriclines and the POC maxima coinciding with the bottom of pycnoclines. The most striking feature in the cruise was that the distribution patterns of [L] and DOC were closely related to 
those of phytoplankton biomass (POC), with much higher values in the surface euphotic zone and subsurface maxima in [L], DOC and POC in the same or similar depths. This close coupling between [L] and other physical and biochemical parameters indicated control of organic ligand concentration by phytoplankton activity. The latter was in turn controlled by physical and chemical conditions e.g. nutrients and light, in the sea.

Similar distribution patterns have been reported for other biochemical materials. These include particulate carbohydrates (Biggs \& Wetzel 1968) and lipids (Parrish 1986), chlorophyll (Goering et al. 1970), and dissolved free amino acids and carbohydrates (Leibezeit et al. 1980).

In autumn, the combined effect of more frequent mixing events and reduced sunlight would result in a light-limiting condition for phytoplankton in temperate waters. On the other hand, nutrient supply to surface water is increased by mixing events, as indicated by slightly higher nutrient concentrations in all stations in the autumn. Therefore, as long as the water column stability allows phytoplankton to stay in surface water, they would continue to grow, taking advantage of higher nutrient availability. No POC measurements were made on this cruise, unfortunately, and it was thus difficult to know the exact pattern of phytoplankton biomass distribution. [L] profiles showed increasing values towards the surface, possibly related to higher phytoplankton activity near the surface.

While the distributions of [L] and other biochemical materials varied seasonally in surface water, (where phytoplankton grow and respond to seasonal changes in meteorological and oceanographic conditions) they remained low and constant with depth and time in deep waters. The main new dissolved organic matter (DOM) source in deep water is the degradation of sinking particulate organic matter (POM), whose concentration is itself very low. POM flux through the water column usually varies seasonally, responding to seasonal changes in [L] in deep water suggested that production of DOM by sinking POM was low and did not change the $[\mathrm{L}]$ value in deep water significantly.

\section{Chromarod TLC characterization}

TLC characterization results (Table 1) demonstrated that most of the copper-complexing sites (> $80 \%$ ) were associated with polar fractions, which were only about $40 \%$ of the total organic carbon isolated. The $60 \%$ in the less-polar fraction contained less than $20 \%$ of copper-complexing sites. This result agreed with the findings of Mills et al. (1982), that polar fractions had a much higher specific copper content.
In the open ocean, samples from surface water not only had a much higher organic carbon content and more complexing sites than those from deep water, but the characteristics of the two were quite different. The specific complexation capacity of isolated organic matter was found to be higher in surface water than in deep water. This is in agreement with the implication of the positive intersection of the [L]-DOC diagram (Figs. $2 b$ and $3 b$ ) i.e. the new DOM fraction has a higher specific complexing capacity than the background fraction.

Calculation of distribution of organic carbon and complexing sites in the operationally defined fractions (Table 1) showed that a much higher proportion of the 'base-mobile' fraction with a higher complexing ability was in surface water than in deep water. Phytoplankton activity must certainly influence the organic ligand in surface water, both in quantity and quality.

Compared with organic matter isolated from the open water sample, that from the shelf surface water sample demonstrated a higher specific complexation capacity and a higher ratio of 'methanol-mobile' fraction to 'acid-mobile' fraction. This was possibly due to the contribution of degradation products of planktonic detritus from bottom sediment on the shelf.

\section{CONCLUSION}

In all the profiles, [L] showed higher values in surface waters and lower values in intermediate and deep waters. The distribution patterns of [L] were found to be closely related to those of biologically related materials, such as POC, DOC and nutrients, and hydrographic conditions. The close coupling between [L] and the indices of phytoplankton activity suggested the importance of the influence of biological activity on organic ligand concentration and distribution in the marine environment. A seasonal variability of $[\mathrm{L}]$ and its distribution pattern was found and could be explained in terms of biological influences which vary according to seasonal changes in metereorologic and oceanographic conditions.

Chromarod TLC characterization of isolated organic ligands suggested that most of the copper-complexing sites were associated with organic matter in the polar fractions, which usually accounted for only about $40 \%$ of the total organic carbon isolated. The results of this study show that organics isolated from surface water had a higher proportion of both organic carbon and complexing sites in the 'base-mobile' fraction, and also had a higher specific complexation capacity than those isolated from intermediate and deep waters, suggesting the influence of biological activity on the quality of copper-complexing organic matter. The long-held 
hypothesis that primary productivity is enhanced by the chelation of metal ions by organic materials produced by phytoplankton (Barber \& Ryther 1969, Barber et al. 1971) is at least partially reinforced by the demonstration that such chelating ligands are indeed produced by phytoplankton in the course of normal growth; a fuller demonstration will require careful studies of ligand production during the time course of the very early stages of growth of phytoplankton populations.

Acknowledgements. This research was made possible by grants to P.J.W from the Natural Sciences and Engineering Research Council of Canada, and by scholarships to X.Z. from the Killam Foundation and the People's Republic of China.

\section{LITERATURE CITED}

Barber, R. T., Dugdale, R. C., Maclsaac, J. J., Smith, R. L. (1971). Variations in phytoplankton growth associated with the source and conditioning of upwelling water. Investigación pesq. 35: 171-193

Barber, R. T., Ryther, J. H. (1969). Organic chelators: factors affecting primary production in the Cromwell Current upwelling. J. exp. mar. Biol. Ecol. 3: 191-199

Biggs, R. B., Wetzel, C. D. (1968). Concentration of particulate carbohydrates at the halocline in Chesapeake Bay. Limnol. Oceanogr. 13: 169-171

Buckley, P. J. M., van den Berg, C. M. G. (1986). Copper complexation profiles in the Atlantic Ocean. A comparative study using electrochemical and ion exchange techniques. Mar. Chem. 19: 281-296

Donat, J. R., Statham, P. J., Bruland, K. W. (1986). An evaluation of a C-18 solid phase extraction technique for isolating metalorganic complexes from central North Pacific Ocean waters. Mar Chem. 19: 85-99

Fisher, N. S., Fabris, J. G. (1982). Complexation of Cu, Zn and $\mathrm{Cd}$ by metabolites excreted from marine diatoms. Mar. Chem. 11: 245-255

Gershey, R. M., Mac Kinnon, M. D., Williams, P. J. leB., Moore, R. M. (1979). Comparison of three oxidation methods used for the analysis of the dissolved organic carbon in seawater. Mar. Chem. 7: 289-306

Goering, J. J., Wallen, D. D., Nauman, R. M. (1970). Nitrogen uptake by phytoplankton in the discontinuity layer of the eastern subtropical Pacific Ocean. Limnol. Oceanogr. 15: $789-796$

Hirose, K., Sugimura, Y. (1983). Relationship between metallic elements and organic matter in marine environments. Pap. Meteorol. Geophys. 34: 291-306

This article was submitted to the editor
Kramer, C. J. M. (1986). Apparent copper complexation capacity and conditional stability constant in North Atlantic waters. Mar Chem. 18: 335-349

Liebezeit, G., Bolter, M., Brown, I. F., Dowson, R. (1980). Dissolved free amino acids and carbohydrates at pycnocline boundaries in the Sargasso Sea and the related microbial activity. Oceanol. Acta 3: 356-362

Mackey, D. J. (1986). Copper-complexing capacity of South Pacific waters. Aust. J. Mar Freshwat. Res. 37: 437-450

McKnight, D. M. Morel, F. M. M. (1979). Release of weak and strong copper-complexing agents by algae. Limnol. Oceanogr 24: 823-837

Mills, G. L., Hanson, A. K. Jr., Quinn, J. G., Lammela, W. R., Chasteen, N. D. (1982). Chemical studies of copperorganic complexes isolated from estuarine waters using C 18 reverse-phase liquid chromatography. Mar. Chem. 11: $151-172$

Parrish, C. C. (1986). Dissolved and particulate lipid classes in the aquatic environment. Ph. D. thesis. Dalhousie University, Halifax

Parsons, T. R., Maita, Y., Lalli, C. M. (1984). A manual of chemical and biological methods for seawater analysis. Pergamon Press, New York

Plavšić, M., Branica, M. (1986). Voltammetric investigation of $\mathrm{Cu}$ (II) interaction with DOM isolated on Sep-Pak C 18 cartridges. Ocean Sci. Engng 11: 99-113

Riley, G. A. (1942). The relationship of vertical turbulence and spring diatom flowering. J. mar. Res. 5: 67-87

Ryther, J. H. (1963). Geographic variations in productivity. In: Hill, M. N. (ed.) The sea, Vol. 2. John Wiley \& Sons, New York

Seritti, A., Pellegrini, D., Morelli, E., Barghiani, C., Ferrara, R. (1986). Copper complexing capacity of phytoplanktonic cell exudates Mar. Chem. 18: 361-357

Smith, P. C., Petrie, B., Mann, C. R. (1978). Circulation, variation and dynamics of the Scotian Shelf and Slope. J. Fish. Res. Bd Can 35: 1067-1083

Sverdrup, H. U. (1953). On conditions for the vernal blooming of phytoplankton. J. Cons. int. Explor. Mer 18: 287-295

Wangersky, P. J. (1976). Particulate organic carbon in the Atlantic and Pacific Oceans. Deep Sea Res. 23: 457-465

Williams, P. M., Oeschger, H., Kinney, P. J (1969). Natural radiocarbon activity of the dissolved organic carbon in the Northeast Pacific Ocean. Nature, Lond. 224: 256-258

Zhou, X., Wangersky, P. J. (1985). Copper complexing capacity in cultures of Phaeodactylum tricornutum: Diurnal changes. Mar. Chem. 17-301-312

Zhou, X., Wangersky, P. J. (1989a). Study of copper-complexing organic ligands: Isolation by a Sep-Pak C 18 column extraction technique and characterization by a Chromarod thin-layer chromatography. Mar. Chem. 26: 21-40

Zhou, X., Wangersky, P. J. (1989b). Changes in copper-complexing organic ligands during spring blooms in the coastal waters of Nova Scotia, Canada. Mar. Ecol. Prog. Ser. 53: $277-284$

Manuscript first received: August 9, 1988

Revised version accepted: February 17, 1989 